Cell Research (2002); 12(2):123-132

http://www.cell-research.com

\title{
Overexpression of heme oxygenase-1 protects smooth muscle cells against oxidative injury and inhibits cell proliferation
}

\author{
Min ZHANG ${ }^{1}$, BAo Hui ZHANG ${ }^{1}$, Li CHEN ${ }^{2}$, Wei $\mathrm{AN}^{2, *}$ \\ ${ }^{1}$ Institute of Sports Medicine, The Third Hospital, Peking University, Beijing 100083, China \\ ${ }^{2}$ Department of Cell Biology, Capital University of Medical Sciences, Beijing 100054, China
}

\begin{abstract}
To investigate whether the expression of exogenous heme oxygenase-1 (HO-1) gene within vascular smooth muscle cells (VSMC) could protect the cells from free radical attack and inhibit cell proliferation, we established an in vitro transfection of human HO-1 gene into rat VSMC mediated by a retroviral vector. The results showed that the profound expression of HO-1 protein as well as HO activity was 1.8- and 2.0fold increased respectively in the transfected cells compared to the non-transfected ones. The treatment of VSMC with different concentrations of $\mathrm{H}_{2} \mathrm{O}_{2}$ led to the remarkable cell damage as indicated by survival rate and LDH leakage. However, the resistance of the HO-1 transfected VSMC against $\mathrm{H}_{2} \mathrm{O}_{2}$ was significantly raised. This protective effect was dramatically diminished when the transfected VSMC were pretreated with ZnPP-IX, a specific inhibitor of HO, for $24 \mathrm{~h}$. In addition, we found that the growth potential of the transfected cells was significantly inhibited directly by increased activity of HO-1, and this effect might be related to decreased phosphorylation of MAPK. These results suggest that the overexpression of introduced hHO-1 is potentially able to reduce the risk factors of atherosclerosis, partially due to its cellular protection against oxidative injury and to its inhibitory effect on cellular proliferation.
\end{abstract}

Key words: Heme oxygenase, retroviral vector, free radical, cell proliferation, vascular smooth muscle cells.

\section{INTRODUCTION}

IHeme oxygenase $(\mathrm{HO})$ is a microsomal enzyme that catalyzes the degradation of heme into biliverdin, which is subsequently reduced to bilirubin, one atom of iron and one molecule of carbon monoxide (CO). There has been a recent explosion of interest in heme oxygenase-1 (HO-1) as its breakdown products play many other vital physiological and pathological roles in diverse biological processes[1]. Enhanced activity of HO-1 has been potentially associated with cellular protection. Conversely, it was found that patient with HO-1 deficiency was more susceptible to en-

\footnotetext{
* Corresponding author: Dr. An Wei, Department of Cell Biology, Capital university of Medical Sciences, 10 You An Men Wai Xi Tou Tiao, Beijing 100054, China Tel: 0086-10-63291921, Fax: 0086-10-63051130,? E-mail: anwei@cpums.edu.cn

Received Feb-25-2002 Revised April-5-2002 Accepted April-12-2002
}

dothelial cell injury[2]. Similarly, HO-1 gene knockout mice revealed more sensitive to a wide variety of oxidative stimuli, such as heme and hydrogen peroxide[3], suggesting that increased HO-1 activity may be beneficial in resistance to oxidants.

Nowadays, more abundant vascular damages are evidenced by the oxygenation of endothelial cells and smooth muscle cells, and the oxygen free radical (OFR) attack seems to contribute dominant pathogenesis of vascular disease in great extent. The elevated plasma levels of low density lipoproteins (LDL) and their oxidative modifications are recognized as main risk factors of atherosclerosis and vascular dysfunction[4]. In addition, oxidative agents and oxidized LDL modulate the function of vascular cells, especially the vascular smooth muscle cells (VSMC), which migrate expansively into intima and 
proliferate noticeably, resulting in the pathology of occluding arterial lesions during atherogenesis[5]. In parallel, more attention has been increasingly paid to antioxidant effect of $\mathrm{HO}-1$ for cardioprotection, because much more cellular protective evidences of HO-1 induction were produced against oxidative damage[6]. It has been recently shown that there is a diminished glutathione-related enzymatic antioxidant shield within human atherosclerosis lesions[7] correlative with the increased expression of HO-1[8]. These phenomenons imply that the induction of $\mathrm{HO}-1$ might function as an alternative antioxidant defense mechanism. In this study, a retroviral vector containing the human HO1 gene was constructed and transfected into rat VSMC to investigate the cellular protection of HO-1 against oxidant-induced injury and the effects of overexpression of HO-1 on cell proliferation.

\section{MATERIALS AND METHODS}

\section{Chemical reagents}

Collagenase I (Sigma); DMEM and fetal calf serum (GIBCO BRL); TRIzol (GIBCO BRL); Lipofectin (BM); random primer labeling kit (Promega); anti-mouse SMC-a-actin monoclonal antibody (Sigma); anti-rat HO-1 polyclonal antibody (Affiniti, UK); anti-rabbit-MAPK (p44/42) polyclonal antibody (Sigma); anti-rabbit-phospho-MAPK (Thr202/Tyr204)polyclonal antibody (Promega); ECL (Santa Cruz); Zinc-protoporphyrin IX (Sigma); MTS (Promega).

\section{Cell culture}

The blood vessel was isolated from thoracic aorta of male Sprague-Dawley rats weighing $200-250 \mathrm{~g}$. One $\mathrm{mm}^{3}$ of tissue slice was made and digested with collagenase I at $37^{\circ} \mathrm{C}$ overnight. VSMC obtained were cultivated in Dulbecco' s Modified Eagles Medium (DMEM) containing $10 \%$ fetal calf serum (FCS) in a $5 \% \mathrm{CO}_{2}$ humidified-atmosphere incubator. The VSMC grown in DMEM medium appeared as a typical morphology of 'hill and valley' The immunohistochemistry staining with a monoclonal antibody against $\alpha$-actin was performed to identify the eventually cocultured fibroblast cells. The retroviral packaging cell line, PA317, was used for the generation of helper-free recombinant retrovirus. The cells were cultured in DMEM supplemented with $10 \%$ FCS, $100 \mathrm{U} / \mathrm{ml}$ penicillin and $100 \mu \mathrm{g} / \mathrm{ml}$ streptomycin. PA317 cells were incubated at $37^{\circ} \mathrm{C}$ in a $5 \% \mathrm{CO}_{2}$ humidified-atmosphere. For experiments, the cells were then sub-cultured into $100 \mathrm{~mm}$-culture dishes or in 24-well plates. The VSMC between passages 2 and 25 were utilized in all experiments.

\section{Construction of the retroviral vector XM6/hHO-1}

$\mathrm{XM} 6$ is a replication-defective retroviral vector that is con- trolled by 5' LTR promoter for transcription[9]. A 987bp HindIIIcleaved fragment of hHO-1 cDNA was released from plasmid pGEM7zf/hHO-1 (kindly provided by Prof. Abraham NG, New York), and inserted into HindIII site of XM6 vector. The orientation of recombinant construct was determined by restriction digestion with ApaI and the correct plamsid construct, designated as XM6/hHO-1, was solely chosen for the subsequent viral infection.

\section{Packaging of retroviral recombinant and transfec- tion of cells[10]}

XM6 and XM6/hHO-1 DNA were transfected into PA317 cells with Lipofectin according to the manufacturer' s manuals. After selected with $400 \mu \mathrm{g} / \mathrm{ml} \mathrm{G} 418$ for $2 \mathrm{w}$, the individual cell-cluster of G418-resistant was formed. The well-isolated clusters were trypsinized and harvested for continuous enrichment to the confluency of $70 \sim 80 \%$. For each isolated clone, the viral titer was determined and only cell clone with titers beyond $1 \times 10^{6}$ colonyforming units (CFU) per ml was exclusively adopted in the following experiments. The medium containing the recombinant XM6/ hHO-1virus was preserved at $-70^{\circ} \mathrm{C}$ till use.

A totally of $2.5 \times 10^{5} \mathrm{VSMC}$ were seeded in $100 \mathrm{~mm}$-dishes and allowed to grow until $50 \sim 70 \%$ of confluence were achieved. The medium was replaced with $5 \mathrm{ml}$ of virus-containing supernatant supplemented by $8 \mu \mathrm{g} / \mathrm{ml}$ polybrene. After incubation for $6 \mathrm{~h}$, the virus supernatant was replaced with fresh complete medium and was incubated for a further $24 \mathrm{~h}$. After selection with $400 \mu \mathrm{g} / \mathrm{ml}$ of G418 for $2 \mathrm{w}$, individual G418-resistant clones were obtained. The VSMC transfected with XM6 or XM6/hHO-1 were nominated VSMC/XM6 and VSMC/HO-1, respectively.

\section{Southern and Northern blot analysis[11]}

Genomic DNA from VSMC, VSMC/XM6 and VSMC/HO-1 cells was isolated. $15 \mu \mathrm{g}$ of each cell DNA was digested with $20 \mathrm{U}$ of BamH I and electrophorized using $1.0 \%$ agarose gel. DNA in the gel was capillary blotted onto nylon membrane (Bio-Rad). Total cellular RNA of the above-mentioned cells and PA317, PA317/ XM6 and PA317/HO-1 as well were extracted using the TRIzol reagent according to the instructions from the manufacturer. A total of $30 \mu \mathrm{g}$ RNA was denatured, electrophorized on $1.0 \%$ agarose gel contained 2.2 M-formaldehyde/ $1 \times$ MOPS and transferred onto a nylon membrane. The membranes were hybridized with either hHO-1 cDNA or 450bp fragment of Neomycin cDNA. To verify the uniformity of RNA loading, a rat S26 cDNA probe was rehybridized as internal control. All the cDNA probes for the hybridization were labeled with $\alpha{ }_{-}^{32} \mathrm{P}$-[dCTP] using random primer labeling kit. The Southern and Northern blot signals on the membrane were visualized by autoradiography on the Kodak X-Omat films (Eastman Kodak Co.) at $-70^{\circ} \mathrm{C}$.

\section{Cell lysis and Western blot}

In parallel to the Northern blot, cellular protein was prepared and Western blot for detection of HO-1 protein expression was performed as described[12]. Briefly, the cells were harvested, washed with phosphate buffer solution (PBS, pH 7.4) and lysed 
with ice-cold lysis buffer (50 mM Tris-HCl, $\mathrm{pH} 7.2 ; 150 \mathrm{mM} \mathrm{NaCl}$; $1 \mathrm{mM}$ EDTA; $1 \%$ Triton X-100; $0.1 \%$ aprotinin; $0.1 \%$ SDS; $1 \mathrm{mM}$ PMSF). The lysate was clarified by centrifugation $\left(14,000 \mathrm{~g}, 4^{\circ} \mathrm{C}\right.$, $30 \mathrm{~min}) .80 \mu \mathrm{g}$ of the protein from supernatant was fractionated by $12 \%$ SDS-PAGE and electrotransferred onto a nitrocellulose membrane. The blots were blocked in $5 \%$ non-fat milk at $4^{\circ} \mathrm{C}$ overnight. In the next day, the membranes were briefly washed twice with Tris-buffered saline containing $0.1 \%$ Tween 20 (TBST) and incubated with rabbit anti-HO-1 polyclonal antibody (1:500 dilution with $0.5 \%$ non-fat milk TBST) for $2 \mathrm{~h}$. Then, the membranes were washed three times each for $10 \mathrm{~min}$ with TBST and incubated with peroxidase-confugated goat anti-rabbit IgG (1: 2000 dilution) for $1 \mathrm{~h}$. Afterward, the membranes were developed with enhanced chemiluminescence (ECL) reagents and the positive signals were exposed to X-ray films. The densities of the immunoblots were scanned with laser densitometer (Bio-Rad).

For detecting the expression and phosphorylation of mitogenactivated protein kinase (MAPK), Western blot was done by the same procedures as above-described, but different concentration of first antibody (1:2000 dilution for anti-MAPK antibody and 1: 1000 dilution for anti-phospho-MAPK antibody) and total $30 \mu \mathrm{g}$ of the protein from cell supernatant was loaded. In addition, $40 \mathrm{mM}$ $\mathrm{NaF}$ was supplemented during preparation of cell lysate to prevent dephosphorylation induced by protein phosphatase.

\section{Measurement of HO-1 activity[13]}

Heme oxygenase activity was measured with the microsomal fractions of culture cells by determining the level of bilirubin formation. The cells were harvested, washed twice with PBS (pH 7.4). The cell suspension was centrifuged at $1,000 \mathrm{~g}$ for $15 \mathrm{~min}$ at $4^{\circ} \mathrm{C}$. The pellets was homogenized and centrifuged at $18,000 \mathrm{~g}$ for $10 \mathrm{~min}$. The supernatant was collected and recentrifuged at 100 , $000 \mathrm{~g}$ for $60 \mathrm{~min}$. Microsomal fractions were resuspended in $0.1 \mathrm{M}$ potassium phosphate buffer ( $\mathrm{pH}$ 7.4). The rat hepatic biliverdin reductase was prepared by $\left(\mathrm{NH}_{3}\right)_{2} \mathrm{SO}_{4}$ precipitation. Microsomes $(0.5 \mathrm{mg})$ were incubated with Hemin $(20 \mu \mathrm{M}), \operatorname{NADP}(0.8 \mathrm{mM})$, Biliverdin reductase (4 mg), glucose-6- phosphate $(4 \mathrm{mM})$, and glucose-6-phosphate dehydrogenase $(1 \mathrm{U})$ in $1 \mathrm{ml}$ for $15 \mathrm{~min}$ at $37^{\circ} \mathrm{C}$ in darkness, and the reaction was stopped by placing the tubes in ice. The optical absorption of bilirubin at $463 \mathrm{~nm}$ was measured against a basal absorption at $530 \mathrm{~nm}$ (extinction coefficient, 40 $\mathrm{mM}^{-1} \mathrm{~cm}^{-1}$ for bilirubin). Heme oxygenase activity is expressed as nanomole of bilirubin per milligram of protein per hour ( $\mathrm{n} M$ bilirubin mg protein ${ }^{-1} \mathrm{~h}^{-1}$ ). The protein of microsomes was determined by the method of Lowry with BSA as a standard.

\section{Measurement of cGMP concentration}

Cellular cGMP content was determined using 125I-labeled radioimmunoaasay kit (Yahui, China). Briefly, the cells were harvested in ice-cold PBS ( $\mathrm{pH} 7.4$ ), sonicated and centrifuged at $8000 \mathrm{~g}$ for $10 \mathrm{~min}$ at $4^{\circ} \mathrm{C}$. Supernatants were stored at $-80^{\circ} \mathrm{C}$ until analysed. cGMP concentration was normalized to protein content by the methods of Lowry.

\section{Cell viability and $L D H$ leakage}

Cell viability was detected by the trypan blue exclusion assay. VSMC were seeded in 24 -well plates $\left(8 \times 10^{4}\right.$ cells/well) and were cultured with fresh complete medium for $24 \mathrm{~h}$ followed by incubation with PBS ( $\mathrm{pH}$ 7.4) containing different concentrations of $\mathrm{H}_{2} \mathrm{O}_{2}(200,400,600 \mu \mathrm{M})$ for $6 \mathrm{~h}$. The culture medium was collected to measure lactate dehydrogenase (LDH) activity according to the method described by Wroblewski F[14]. Subsequently, the cells were trypsinized with $0.1 \mathrm{ml}$ of $0.1 \%$ trypsin-EDTA followed by neutralization with $0.4 \mathrm{ml}$ of serum-contained culture medium. After stained with trypan blue, the numbers of cells excluding or stained with trypan blue were counted by using a hemocytometer under light microscope. Cell viability was calculated as the percentage of viable (unstained) cells of the total (stained and unstained) cells.

\section{Cell growth and flow cytometry assay}

Cell growth was measured by non-radioactive proliferation assay based upon the cellular conversion of the tetrazolium salt, MTS [3-(3,5-dimethylthialzol-2-yl)-5-(3 carboxymethoxypheny)2-(4-sulphophenyl)-2H-tetrazolium], into a formazan product that is soluble in culture medium[15]. Briefly, VSMC, VSMC/XM6 and VSMC/HO-1 cells were cultured in serum-starved medium for synchronization of cell cycle. $24 \mathrm{~h}$ later, the above three cells were trypsinized and inoculated into 96 -well plates $\left(5 \times 10^{3} \mathrm{cells} / \mathrm{well}\right)$. MTS reagent was added into the medium $2 \mathrm{~h}$ prior to measurement and the absorption was determined with Microplate Reader (Bio-Rad) at $490 \mathrm{~nm}$.

Flow cytometric determination of DNA content was used as another index of cell proliferation (16). The synchronized cells were trypsinized, harvested and inoculated into 6-well plates $\left(5 \times 10^{5}\right.$ cells/well). $24 \mathrm{~h}$ later, cells were collected, washed with PBS and centrifuged by at $2000 \mathrm{rpm}$ for $10 \mathrm{~min}$. The pellets of cells were resuspended in $80 \%$ ethanol and stored at $4^{\circ} \mathrm{C}$ for $24 \mathrm{~h}$. The cells were washed twice with PBS and the pellet was resuspended in PBS containing $100 \mu \mathrm{g} / \mathrm{ml}$ RNase A, incubated at $37^{\circ} \mathrm{C}$ for 30 min, stained with $50 \mu \mathrm{g} / \mathrm{ml}$ phosphatidylinositol (PI), and analyzed by flow cytometry for DNA analysis.

\section{Statistical analysis}

All values were expressed as means \pm SD. Statistical significance was determined by one-way ANOVA. $\mathrm{P}$ values $<0.05$ were considered significant.

\section{RESULTS}

\section{Efficiency of gene transfer and overexpression of hHO-1 gene}

The G418-resistant PA317 cells transfected either with XM6 or XM6/hHO-1 were evaluated for the potential of the production of recombinant retrovirus in culture medium. The results showed that the titers of $1.3 \times 10^{6} \mathrm{CFU} / \mathrm{ml}$ in PA317/XM6 and $1.2 \times 10^{6} \mathrm{CFU} / \mathrm{ml}$ in PA317/HO-1 were obtained, 

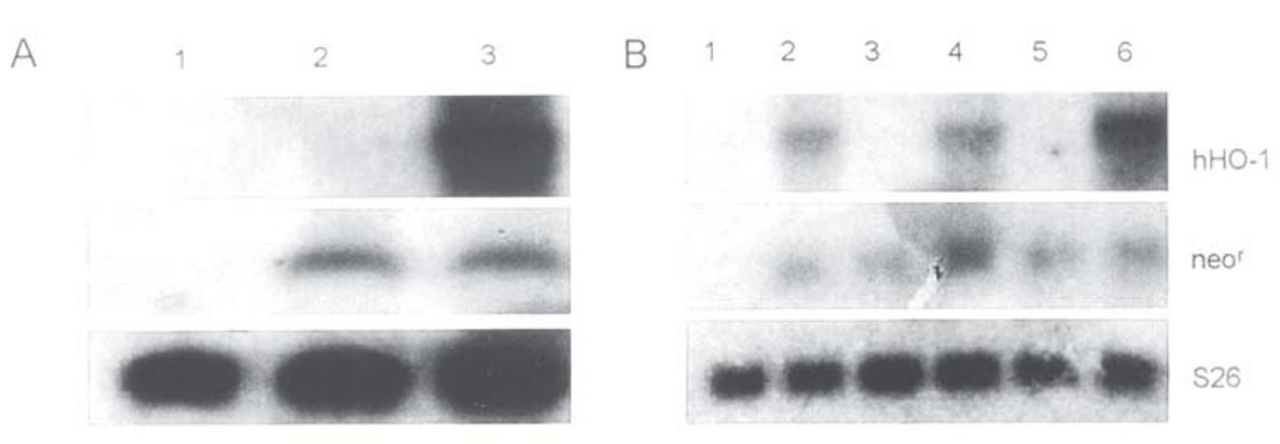

Fig 1. Detection of hHO-1, neo ${ }^{\mathrm{r}}$ and $\mathrm{S} 26$ transcripts by Northern blot in RNA extracted from PA317 cell (A) and VSMC (B). A: wild type PA317 (lane 1), XM6-transfected PA317 (lane 2), hHO-1transfected PA317 (lane 3); B: wild-type VSMC (lane 1), two clones of XM6-transfected VSMC (lane 3 and 5), three clones of hHO-1transfected VSMC (lane 2, 4 and 6).

respectively. The Northern blot analysis in Fig 1A indicated that human HO-1 mRNA was solely expressed in PA317/HO-1, but not in PA317/XM6 and PA317 wild-type cells. After infected by PA317/XM6 and PA317/HO-1 virus and screened with the G418, VSMC clusters were obtained. Total RNA from 5 individual cell clones, of which three were PA317/ HO-1-infected and two were PA317/XM6, was prepared and expression of hHO-1 gene was analyzed. As indicated in Fig 1B, all the retrovirus-infected VSMC could equally express S26 and neo ${ }^{\mathrm{r}}$, however, neither wild-type VSMC nor XM6-transfected cells produced a positive band of hHO-1. hHO-1 mRNA was detected only in HO-1-transfected cells. Meanwhile, an equalization of S26 signals revealed the unity amounts of RNA loaded on to the filters in each lane of the paired experiments. Genomic DNA hybridization with hHO-1 cDNA probe as viewed in Southern blot strongly demonstrated the integration of recombinant DNA into the host VSMC (data not shown).

Enhancement of HO activity and HO-1 protein expression in VSMC/HO-1 cells

The basal levels of $\mathrm{HO}$ activity between wild-type VSMC and XM6-transfected VSMC were found no significance $(P>0.05)$. Whiles, HO activity in the hHO-1-transfected VSMC was remarkably increased by 2.0 -fold compared with that in control VSMC, $\mathrm{P}<0.05$ (Fig 2A). Meanwhile, HO-1 protein expression gave rise to a strong signal for the HO-1-transfected VSMC. The enhancement of HO
A

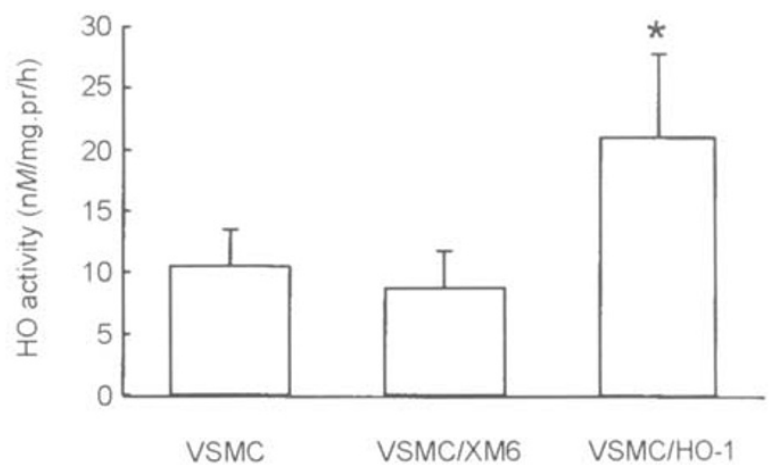

B
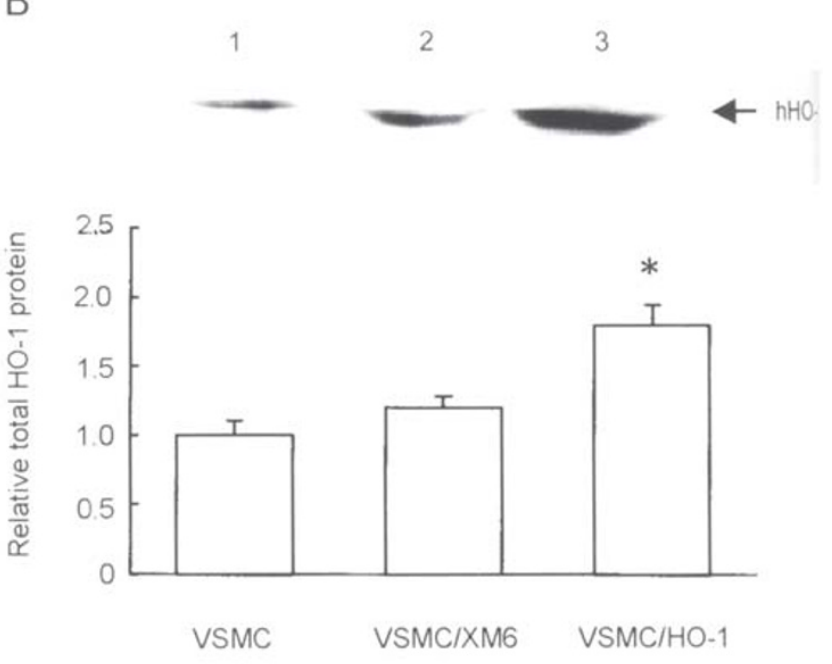

Fig 2. Detection of $\mathrm{HO}$ activity (A) and HO-1 protein expression in the wild-type, XM6-transfected and hHO-1transfected VSMC by Western blot analysis (B). Values are expressed as means \pm SD of 3 experiments. 1 . VSMC; 2 . VSMC/ $\mathrm{XM} 6$; 3. VSMC/HO-1. ${ }^{*} \mathrm{P}<0.05$ vs wild-type VSMC. 
A
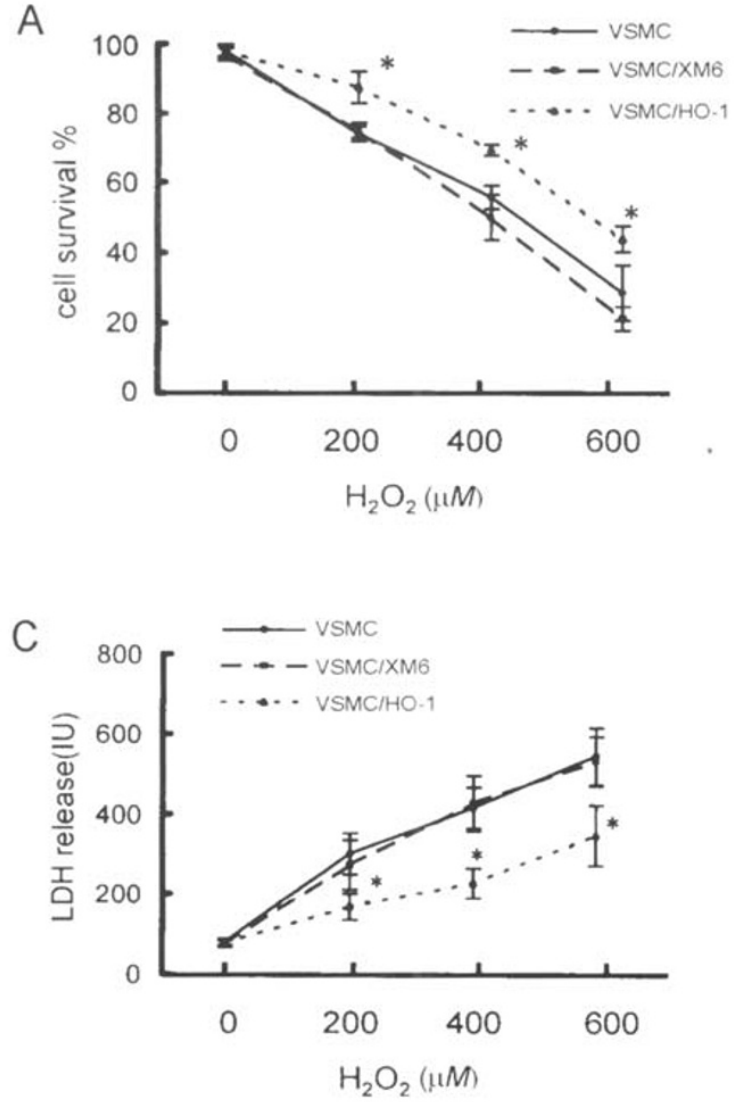

$\mathrm{B}$
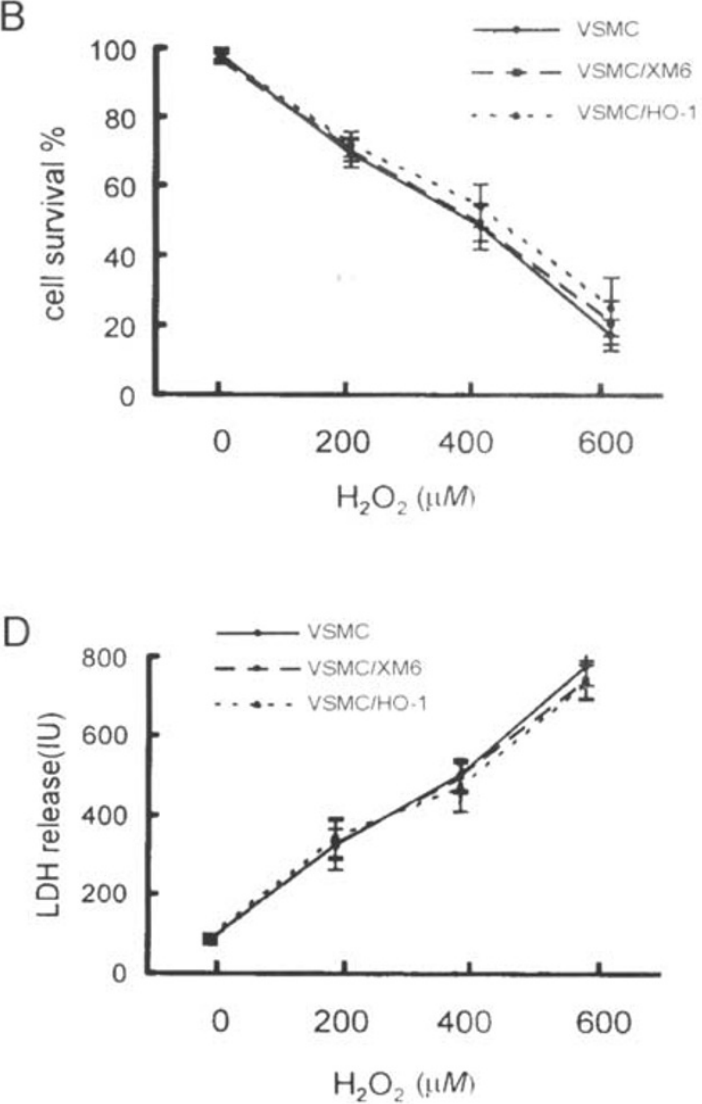

Fig 3. Cells survival (A,B) and LDH leakage (C,D) of the wild-type, XM6-transfected and hHO-1-transfected VSMC after exposure to different concentrations of $\mathrm{H}_{2} \mathrm{O}_{2}$. Data are shown as means 了SD of 6 independent experiments. A and C: treatment with $\mathrm{H}_{2} \mathrm{O}_{2}$ for $6 \mathrm{~h}$. B and D: pretreatment with $20 \mu \mathrm{M} \mathrm{ZnPP}$-IX for $24 \mathrm{~h}$ followed by exposure to $\mathrm{H}_{2} \mathrm{O}_{2}$ for $6 \mathrm{~h}$. ${ }^{*} \mathrm{P}<0.05$ vs wild-type VSMC.
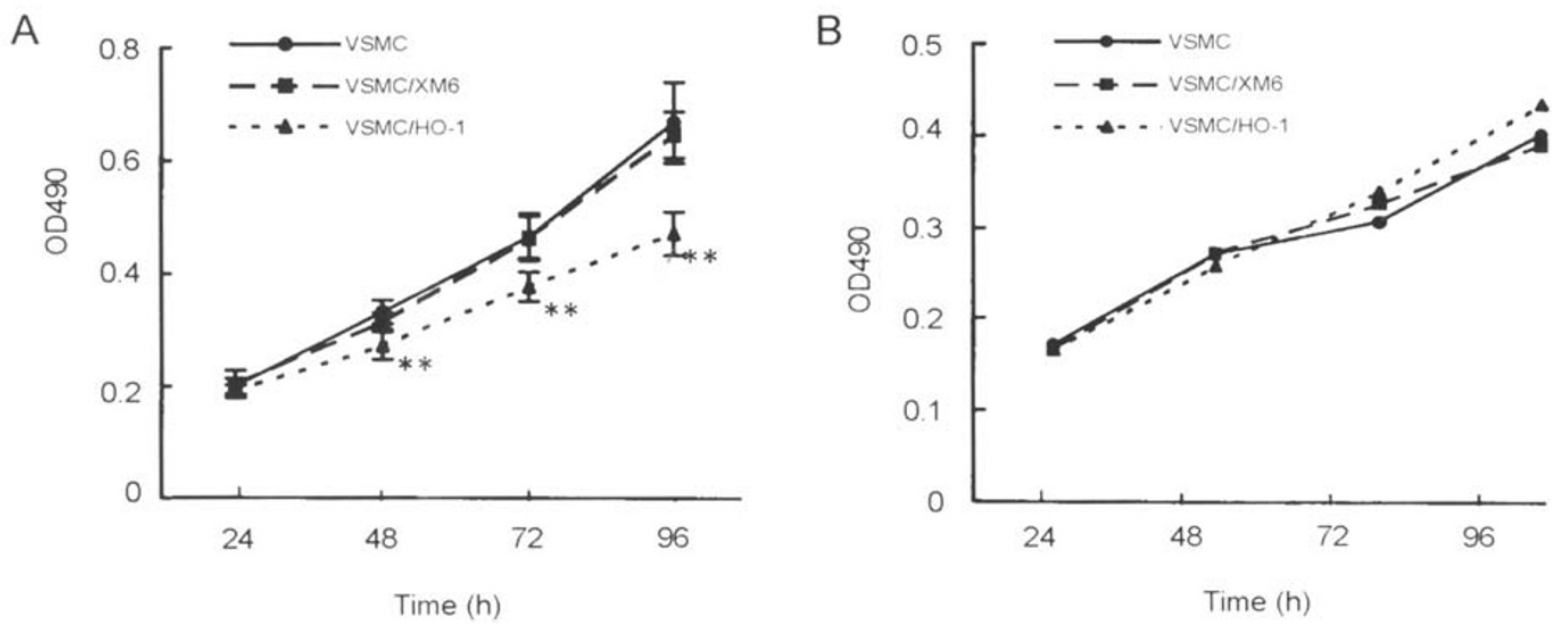

Fig 4. Effects of overexpression of hHO-1 on the cell growth. A: cells were arrested by serum starvation for 24 $\mathrm{h}$ and then exposed to $10 \%$ FBS to restimulate; B: pretreatment with $20 \mu \mathrm{M}$ ZnPP-IX for $24 \mathrm{~h}$. Data are shown as means \pm SD of 6 independent experiments performed in duplicate. ${ }^{* *} \mathrm{P}<0.01$ vs. wild-type VSMC 
A
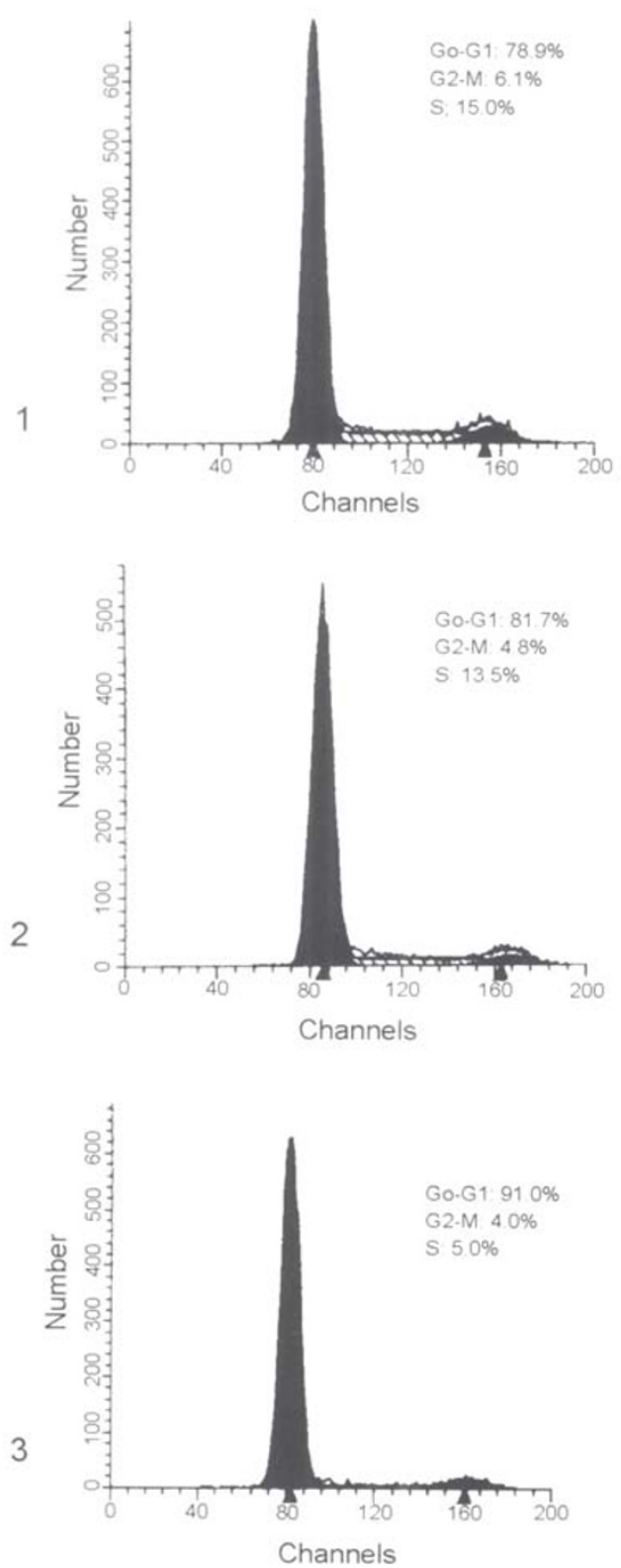

$\mathrm{B}$
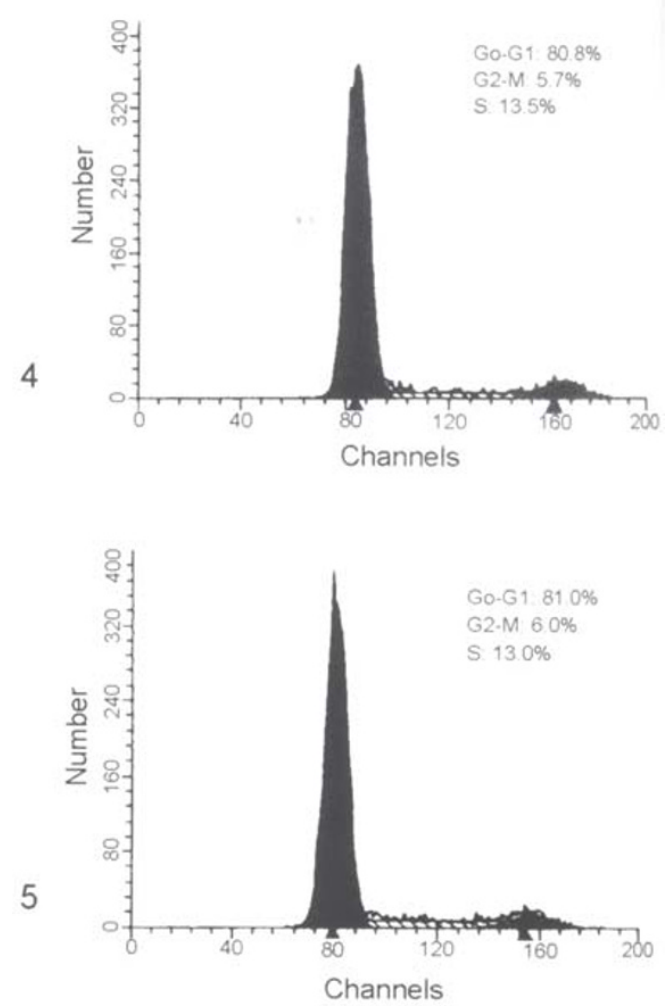

6

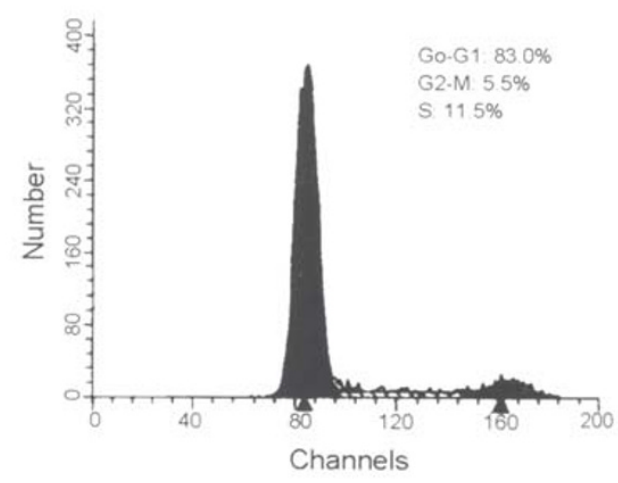

Fig 5. Effects of over-expression of hHO-1 on the cell cycle phase. A: The synchronized cells were exposed to $10 \%$ FBS to restimulate for $24 \mathrm{~h}$; B: pretreatment with $20 \mu \mathrm{M}$ ZnPP-IX for $24 \mathrm{~h}$. 1,4: wild-type VSMC; 2,5: VSMC/ XM6; 3,6: VSMC/HO-1.

activity was apparently identical to the hHO-1 mRNA expression. The quantitative evaluation of Western blot signals as scanned by densitometry indicated that HO-1 protein in hHO-1-transfected VSMC was increased 1.8-fold compared with nontransfected cells (Fig 2B). These data clearly demonstrated that the enhancement of $\mathrm{HO}$ activity was coordinated with the protein overexpression ofHO-1. Moreover, the introduction of exogenous HO-1 gene mediated by retrovirus allowed the functional expression of this foreign gene in the target VSMC.

Anti-oxidant effects of hHO-1 gene transfer

The exposure of VSMC to a series of concentration of $\mathrm{H}_{2} \mathrm{O}_{2}(200 \sim 600 \mu M)$ led to severe leakage of intracellular $\mathrm{LDH}$. The results showed that VSMC, 
VSMC/XM6 and VSMC/HO-1 cells without exposure to $\mathrm{H}_{2} \mathrm{O}_{2}$ were more than $97 \%$ viable. Whereas, the treatment of these cells with $\mathrm{H}_{2} \mathrm{O}_{2}$ for $6 \mathrm{~h}$ resulted in apparent increment in cell death and $\mathrm{LDH}$ leak-out as dose-dependent pattern. However, the cell damages in hHO-1-transfected VSMC, under similar dose of $\mathrm{H}_{2} \mathrm{O}_{2}$, were significantly relieved as compared with nontransfected or XM6-transfected VSMC. As shown in Fig 3A and Fig 3C, the more survivals of hHO-1 transfected VSMC were observed and $\mathrm{LDH}$ leakage was markedly declined under a sub-lethal or lethal dose of $\mathrm{H}_{2} \mathrm{O}_{2}$. In contrast, the protective effect was re-masked, if the cells were pretreated with a defined inhibitor of $\mathrm{HO}$, zinc-protoporphyrin $(20 \mu \mathrm{M})$ for $24 \mathrm{~h}$ (Fig 3B, Fig 3D). These results indicated that overexpression of gene-transferred hHO-1 in rat VSMC was able to enhance the cell resistant to oxidant-induced injury elicited by exposure to $\mathrm{H}_{2} \mathrm{O}_{2}$.

\section{Inhibition of cell proliferation}

As shown in Fig 4A, hHO-1-transfected VSMC appeared a slower growth rate than that of wild-type VSMC and XM6-transfected VSMC. The antiproliferative effect of overexpression of hHO-1 was also evidenced by flow cytometry assay. Although VSMC in the normal arterial media in vivo are quiescent and contractile, the isolation and culture of VSMC in vitro are associated with a similar phenotypic change from a contractile to a synthetic, proliferative phenotype. As shown in Fig 5A, 15\% of the wide-type VSMC entered the S-phase of the cell cycle, whereas, only $5 \%$ of hHO-1 transfected VSMC occurred in S-phase, and 91\% of hHO-1-transfected cells were in the growth-arrested phase (G0/G1) of the cell cycle. In addition, transfection of vector XM6 in VSMC had no effect on cell DNA synthesis. In contrast, The anti-proliferation effect of HO-1 was reversed by pretreating the cells with $20 \mu \mathrm{M} \mathrm{ZnPP}$ IX for $24 \mathrm{~h}$ (Fig 4B, Fig 5B). These results indicated that overexpression of gene-transferred hHO-1 in rat VSMC was able to inhibit cell proliferation.

\section{Increase of cellular cGMP and decrease of MAPK} phosphorylation

Although there was no significant difference in the basal level of endogenous cellular cGMP between non-transfected and XM6-transfected VSMC (1.07 \pm 0.38 and $1.19 \pm 0.33 \mathrm{pmol} / \mathrm{mg}$ respectively), the
cGMP content in hHO-1-transfected VSMC was markedly increased $(2.68 \pm 0.59 \mathrm{pmol} / \mathrm{mg})$ compared with that in wild-type VSMC $(\mathrm{P}<0.01)$. Moreover, the elevation of cGMP level could be diminished by pretreatment of all cells with ZnPP-IX for $24 \mathrm{~h}(0$. $84 \pm 0.24,0.91 \pm 0.17$ and $1.11 \pm 0.2 \mathrm{pmol} / \mathrm{mg}$, respectively), indicating that the augmentation of cGMP level was mediated by the overexpression of HO-1.

It is well known that MAPK is a converging point for various signal pathways leading to cell proliferation. To investigate the possible mechanism of the anti-proliferative effect of HO-1, the p44/42MAPK expression and MAPK phosphorylation level were measured using Western blot. As shown in Fig 6 , the expression of $\mathrm{p} 44 / 42-\mathrm{MAPK}$ was no significant difference in three types of the cells, but the MAPK phosphorylation level in hHO-1-transfected VSMC was $43 \%$ decreased compared with that in wild-type VSMC $(\mathrm{P}<0.01)$.

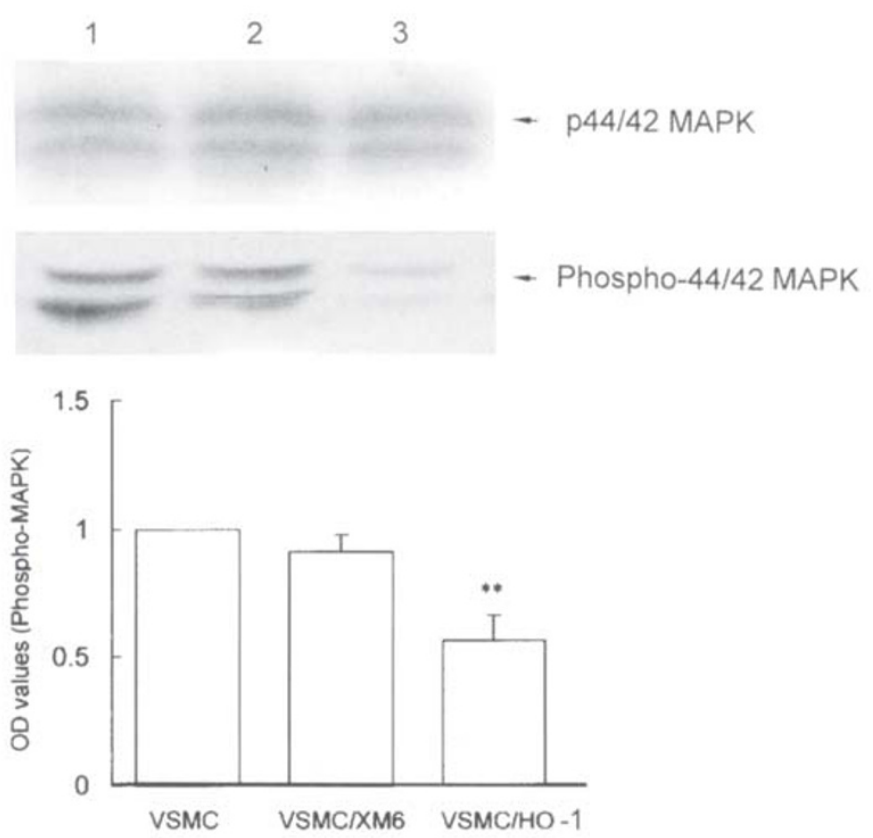

Fig 6. Detection of p44/42 MAPK expression and phosphorylation in the VSMC nontransfected or transfected with XM6 or XM6/hHO-1 by Western blot analysis. Values are expressed as means \pm SD of 3 experiments. 1 . wild-type VSMC; 2. VSMC/XM6; 3. VSMC/HO-1. ** $\mathrm{P}<0.01$ vs wild-type VSMC

\section{DISCUSSION}

Transfection of mammal cells with retroviral vector possesses considerable advantages including relatively high infective efficiency and stable expression. 
Although adenovirus has been used in other experiment for investigate the roles of HO-1 in the development of atherosclerosis[17], the major shortcomings of this viral vector are often reported as to high immunogenicity which may lead to inflammatory reactions or even death in the host[18]. Thus, retroviral vector is more suitable for delivering a foreign gene into mammalian cells[19]. In this study, the retrovirus containing hHO- 1 was constructed and then introduced into the VSMC, the abundant virus titers as $1.3 \times 10^{6} \mathrm{CFU} / \mathrm{ml}$ were obtained, indicating the sufficient infection rate of hHO-1 recombinant. Moreover, it had been shown in Southern, Northern and Western blot that the hHO$1 \mathrm{cDNA}$ was reliably integrated into the host chromosomal DNA and could be efficiently transcribed and translated. The increase in HO-1 protein expression was parallel to its enhancing activity in hHO-1 transfected VSMC compared with the control cells. Furthermore, hHO-1 mRNA signals could be obviously detected after 25 passages of VSMC/ HO-1 cells. The above results indicated that the construction strategy of the recombinant vector was correctly performed and the retrovirus containing $\mathrm{hHO}-$ 1 could be stably and efficiently expressed in transfected-VSMC. In fact, several other transgenic cell lines for expression of the specific target genes had been established in this lab by using retroviral [11], [20].

To date, three types of $\mathrm{HO}$ isoenzymes named as HO-1, 2, 3 and encoded by different genes have been identified[21],[22]. In vascular system, only HO-1 and HO-2 are expressed. HO-2 is a constitutive protein that plays a regulatory role in physiological process. As previous report, HO-1 is proposed as a protective protein as heat shock protein that is inducible by a number of stressful stimuli, such as hypoxia, heavy metals, oxidant-LDL and endotoxin. It was suggested in the considerable data that the increase in HO-1 expression in different cell types such as endothelial cells[23], cardiomyocytes[24], fibroblasts [25] etc may yield protective effect on the insulated cells against oxidation injury. Clark[26] reported that hemin-mediated increase in $\mathrm{HO}-1$ protein expression resulted in high resistance to VSMC injury caused by an oxidant-generating system, but expression of HO-1 induced by hemin pre-treatment appeared non-tissue specific. In this study, more direct findings were obtained that hHO1 gene-expressed VSMC could raise obvious resistance against free radical injury of $\mathrm{H}_{2} \mathrm{O}_{2}$. Moreover, the protection of HO-1 gene was reasonable declined if the transfected cells were pretreated with HO-1 specific inhibitor ZnPP-IX for $24 \mathrm{~h}$. It implies that the HO-1, apart from classical free radical scavengers, could be an alternative molecule to protect the vascular cells during oxidant-injury. Although the precise mechanisms by which HO-1 confers to such cellular protection have not been fully understood, the following hypotheses relevant to this protection have been taken into account: a) depletion of the oxidant heme, as well as production of biliverdin and bilirubin which are important physiological OFR scavengers[27], b) elevation of intracellular $\mathrm{Fe}^{2+}$ level to facilitate ferritin up-regulation which decreases OFR induction[21], c) relaxation of vascular tension and inhibition of platelet aggregation through endogenous CO generation[28].

It is reported that active oxygen species is not only harmful to vascular cells, but also might be act as stimuli to VSMC growth[29]. Since the VSMC were supposed to migrate from medial layer into the new-grown intima and are rapidly proliferated as consequence of endothelial damage, therefore it has been believed that accumulation of "immigrant VSMC" play an important role for the initiation of atherosclerosis. Our results showed that overexpression of HO-1 could protect cells against oxidant-injury on one hand, importantly, increase of HO-1 activity might suppress VSMC proliferation on the other. More recently, Liu and colleagues[30] reported that adenovirus-mediated HO-1 expression could stimulate apoptosis in VSMC. As more confirmed evidence, we here reported that overexpression of HO-1 in the transfected VSMC could slow down the cell growth. It was revealed that CO derived from VSMC could increase vascular cGMP and arrest the proliferation of hypoxic VSMC [31],[32], however, there are no doubt some precise molecular mechanisms for these effects remain uncovered. We here found for the first time that there might exist some intrinsic relationships between the anti-proliferative effect of HO-1 and the decrease of MAPK phosphorylation. Suhasini[33] reported 
that G-kinase inhibited the Ras/MAPK pathway at the level of c-Raf kinase. For this reason characterization of MAPK activity and its mediated- signaling in HO-1 transfected cell will probably explain the mechanisms of cell-growth arrest. The paradoxical phenomenon of cGMP enhancement with MAPK dephosphorylation in the transfected cells reflexes "cross talk" between these two signaling cascades, thereafter, the increase of cGMP might be apparently a counter-regulatory mechanism for attenuating the MAPK activation pathway.

It has been emphasized that ORF is involved in fundamental pathogenesis in many diseases such as atherosclerosis, hypertension, ischemia-reperfusion injury. In the progress of atherosclerosis, under certain circumstances when some of the critical antioxidant enzymes including glutathione and superoxide dismutase (SOD) were reduced and the production of $\mathrm{NO}$ in endothelial cells was diminished, the activation of $\mathrm{HO} / \mathrm{CO}$ pathway will build up an alternative important defense against oxidative insult. Recently, Juan et al[34] reported that adenovirus-mediated HO-1 gene transfer could inhibit the development of atherosclerosis in apoE-deficient mice. We here found that the over-expression of hHO-1 in the transfected VSMC could directly and significantly inhibit VSMC proliferation. Therefore, the activation of $\mathrm{HO} / \mathrm{CO}$ signal pathway might be speculated to prevent the formation and development of atherosclerosis, particularly by restoring the balance of anti-oxidants and pro-oxidants in the vascular wall, inhibiting cell proliferation and maintaining blood flow.

\section{ACKNOWLEDGEMENT}

This work was kindly supported by National Natural Science Foundation of China (No. 39670308).

\section{REFERENCES}

[1] Galbraith R. Heme oxygenase: who needs it?. PSEBM 1999; 222:299-305.

[2] Yachie A, Niida Y, Wada T et al. Oxidative stress causes enhanced endothelial cell injury in human heme oxygenase-1 deficiency. J Clin Invest 1999; 103:129-35.

[3] Poss KD, Tonegawa S. Reduced stress defense in heme oxygenase-1 deficient cells. Proc Natl Acad Sci USA 1997; 94:10925-30.

[4] Witztum JL, D. Steinberg. Role of oxidized low density lipoprotein in atherogenesis. J Clin Invest 1991; 88:
1785-92.

[5] Schwartz SM, D deBlois, ER O払rien. The intima: soil for atherosclerosis and restenosis. Circ Res 1995; 77:44565.

[6] Yoshida T, Maulik N, Ho YS, Alam J, Das DK. Hmox-1 constitutes an adaptive response to effect antioxidant cardioprotection. Circulation 2001; 103:1695-701.

[7] Lapenna D, de Gioia S, Ciofani G et al. Glutathione-related antioxidant defences in human atherosclerotic plaques. Circulation 1998; 97:1930-34.

[8] Wang LJ, Lee TS, Lee FY, Pai RC, Chau LY. Expression of heme oxygenase-1 in atherosclerotic lesions. Am J Pathol 1998; 152:711-20.

[9] Scarpa M, Cournoyer D, Muzny DM, Moore KA, Belmont JW, Caskey CT. Characterization of recombinant helper retroviruses from Moloney-based vectors in ecotropic and amphotropic packaging cell lines. Virology 1991; 180(2): 849-52.

[10] Cepko C. Introduction of DNA into mammalian cells. In: Ausubel FM, Brent R, Kingston RE, eds. Short Protocols in Molecular Biology, 3rd ed. New York: John Wiley \& Sons, 1995, 1-49.

[11] Bai JX, Zhu XG, Zheng XC, Wu YJ. Overexpression of CuZnSOD gene suppresses the growth of hepatocellular cancer cell line HepG2. Chinese Medical Journal 1998; 111(9):789-92.

[12] Vesely MJJ, Exon DJ, Clark JE, Foresti R, Green CJ, Motterlini R. Heme oxygenase-1 induction in skeletal muscle cells: hemin and sodium nitroprusside are regulators in vitro. Am J Physiol 1998; 275:C1087-94.

[13] Li YM, Liu JC, Zhang M et al. Alterations of heme oxygenase in cardiovascular system of rat during sepsis. $J$ Beijing Med Univ 1999; 31:497-500. (in Chinese with English abstract)

[14] Wroblewski F. Lactate dehydrogenase activity in blood. Proc Sci Exp Biol Med 1995; 90:210-8.

[15] Goodwin CJ, Holt SJ, Downes S, Marshall NJ. Microculture tetrazolium assays: a comparison between two new tetrazolium salts, XTT and MTS. J Immunol Methods 1995; 179(1):95-103.

[16] Ohtsubo M, Roberts JM. Cyclin dependent regulation of G1 in mammalian fibroblasts. Science 1993; 259:190811.

[17] Tulis DA, Durante W, Liu X, Evans AJ, Peyton KJ, Schafer AI. Adenovirus-mediated heme oxygenase-1 gene delivery inhibits injury-induced vascular neointima formation. Circulation 2001; 104:2710-5.

[18] Senior K. Gene therapy: a rocky start to the new millennium. Mol Med Today 2000; 6(3):93.

[19] Romano G, Pacilio C, Giordano A. Gene transfer technology in Therapy: current applications and future goals. Stem Cells 1999; 17:191-202.

[20] Gao D, An W, Dai J. Retrovirus-mediated herpes simples virus thymidine kinase gene therapy approach for hepatocellular carcinoma. Cell Research 1999; 9:225-35.

[21] Maines MD. The heme oxygenase system: a regulator of second messenger gases. Annu Rev Pharmacol Toxicol 1997; 37:517-54.

[22] McCoubrey WK, Huang TJ, Maines MD. Isolation and 
characterization of a cDNA from the rat brain that encodes hemoprotein heme oxygenase-3. Eur J Biochem 1997; 247:725-32.

[23] Yang LM, Shuo Q, Abraham NG. Retrovirus-mediated HO gene transfer into endothelial cells protects against oxidant-induced injury. Am J Physiol 1999; 277:L12733.

[24] Borger DR, Essig DA. Induction of HSP32 gene in hypoxic cardiomyocytes is attenuated by treatment in Nacetyl-1-cysteine. Am J Physiol 1998; 274:H965-73.

[25] Dennery PA, Sridhar KJ, Lee CS, Wong HE, Shokoohi V, Rodgers PA, Spitz DR. Heme oxygenase-mediated resistance to oxygen toxicity in hamster fibroblasts. J Biol Chem 1997; 272:14937-42.

[26] Clark JE, Foresti R, Green CJ, Motterlini R. Dynamics of haem oxygenase-1 expression and bilirubin production in cellular protection against oxidative stress. Biochem J 2000; 348:615-9.

[27] Stocker R, Yamamoto Y, McDonagh AF, Glazer AN, Ames $\mathrm{BN}$. Bilirubin is an antioxidant of possible physiological importance. Science 1987; 235:1043-46.

[28] Foresti R, Motterlini R. The heme oxygenase pathway and its interaction with nitric oxide in the control of cellular homeostasis. Free Rad Res 1999; 31:459-75.

[29] Rao GN, BC Berk. Active oxygen species stimulate vas- cular smooth muscle cell growth and proto-oncogene expression. Circ Res 1992; 70:593-99.

[30] Liu XM, Chapman GB, Wang H, Durante W. Adenovirusmediated heme oxygenase-1 gene expression stimulates apoptosis in vascular smooth muscle cells. Circulation 2002; 105:79-84.

[31] Morita T, Perrella MA, Lee ME, Kourembanas S. Smooth muscle cell-derived carbon monoxide is a regulator of vascular cGMP. Proc Natl Acad Sci USA 1995; 92:14759.

[32] Morita T, Mitsialis SA, Koike H, Liu Y, Kourembanas S. Carbon monoxide controls the proliferation of hypoxic vascular smooth muscle cells. J Biol Chem 1997; 272: 32804-9.

[33] Suhasini M, Li H, Lohmann SM, Boss GR, Pilz RB. Cyclic-GMP-dependent protein kinase inhibits the Ras/ mitogen-activated protein kinase pathway. Mol Cell Biol 1998; 18:6983-94.

[34] Juan SH, Lee TS, Tseng KW et al. Adenovirus-mediated heme oxygenase- 1 gene transfer inhibits the development of atherosclerosis in apolipoprotein E-deficient mice. Circulation 2001; 104:1519-25. 